\title{
Treatment of fragility ankle fractures using hindfoot nail, systemic review
}

\section{Mohammed Elmajee $^{\mathrm{a}}$, Abdullah Gabr ${ }^{\mathrm{c}}$, Ahmed Aljawadi ${ }^{\mathrm{b}, *}$, Matthew Strang ${ }^{\mathrm{d}}$, Shoaib Khan ${ }^{\mathrm{e}}$, Sivashankaren Munuswamy ${ }^{\mathrm{f}}$, Anand Pillai ${ }^{\mathrm{b}}$, Dominic Sprott ${ }^{\mathrm{c}}$}

a ST4 Spine Department, Royal Orthopaedic Hospital NHS Foundation Trust, Birmingham, B31 2AP, UK

b Trauma and Orthopaedics, Wythenshawe Hospital, Manchester, M23 9LT, UK

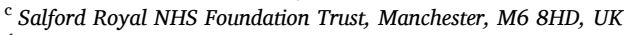

d Trauma and Orthopaedics, North Manchester General Hospital, Manchester, M8 5RB, UK

${ }^{\mathrm{e}}$ ST4 Trauma and Orthopaedics, Warrington Hospital, Warrington, WA5 1QG, UK

${ }^{\mathrm{f}}$ Sandwell Hospital, West Bromwich, B71 4HJ, UK

\section{A R T I C L E I N F O}

\section{Keywords:}

Complication

Elderly

Management

Ankle

Fragility

Surgery

\begin{abstract}
A B S T R A C T
With an aging population, the prevalence of fragility ankle fractures is rising. The surgical management of these injuries is challenging and associated with high rates of complications.

An extensive literature review (inception of data until September 2019) was undertaken to locate previous studies that have addressed the same topic. Seven studies met the inclusion criteria. The post-operative Olerud and Molander scores were comparable/slightly lower than pre-injury scores. Bony union was achieved in $90.3 \%$ $100 \%$ of cases.

Hindfoot nails, when used to treat fragility ankle fractures, can facilitate early rehabilitation and restoration of function among elderly osteoporotic patients.
\end{abstract}

\section{Introduction}

There is a rising prevalence of fragility ankle fractures within the elderly population. These injuries are associated with significant morbidity and mortality and are most commonly seen in elderly osteoporotic females. ${ }^{1},{ }^{2}$ The incidence of fragility ankle fractures is currently estimated to be around 150 per 100,000 people annually and is anticipated to rise to around 269 per 100,000 by $2030 .{ }^{1}$ The management of fragility fractures can be challenging. The aim of treating a young patient with ankle fractures is to restore the congruency of the talo-tibial joint to reduce in incidence of osteoarthritis later in life. However, for fragility ankle fracture that affects patients older than 65 years of age, the aim of surgery is to restore mobility, preserve function and to prevent complications related to non-weight-bearing. ${ }^{3-6}$

Achieving and maintaining anatomical reduction is often difficult due to the complex fracture pattern associated with fragility ankle fractures. ${ }^{7,8}$ Following the successful reduction in plaster, Willett, Hearn, \& Cuncins observed that these injuries often went on to lose reduction and drift into valgus malalignment, thus increasing the likelihood of developing a malunion or non-union. ${ }^{7}$ Furthermore, Buckingham, Hepple, \& Winson observed that patients treated conservatively were at a high risk of complications due to prolonged periods of immobilization such as; pressure sores, deep vein thrombosis (DVT), urinary tract infection (UTI) and pneumonia. ${ }^{6}$

On the other hand, Operative treatments are associated with significant complications. Patient factors such as medical comorbidities, increasing age, and poor mobility are associated with an increased risk of surgery-related morbidity and mortality. ${ }^{6}$ Patients suffering fragility ankle fractures often possess osteoporotic bone, poor-quality skin and soft tissues, which can contribute to the failure of a surgical fixation. ${ }^{6,7}$

There has been a reported recent trend toward intramedullary (IM) nailing for the treatment of osteoporotic ankle fractures. Such fixation techniques have less impact on soft tissues and can facilitate immediate postoperative weight bearing, resulting in a lower risk of complications. Despite these benefits, surgeons have failed to routinely adopt the use of IM nailing techniques to treat ankle fractures in the same way IM nails are used in the management of tibial and femoral fractures. ${ }^{3,9}$ This systematic review aims to investigate the role of hindfoot nails (HFN) in the treatment of fragility ankle fractures. We aim to review the available evidence published on the functional recovery observed in patients following treatment with HFN and the observed complications among the literature.

\footnotetext{
* Corresponding author.

E-mail addresses: Mohammedelmajee@doctors.net.uk (M. Elmajee), ahmed.aljawadi@mft.nhs.uk (A. Aljawadi).
} 


\section{Methodology and methods of investigation}

A review of the current literature was conducted to identify recent systematic reviews on the use of HFN in the treatment of fragility ankle fractures. Our electronic search included the following databases; Web of Sciences, Cochrane Database of Systematic Review, MEDLINE, CINHAL, and Academic Search Premier. We also conducted a web search using Google Scholar (Table 1 summarises the search terms).

Literature search showed one previous published systematic review titled; The role of intramedullary fixation in ankle fractures - A systematic review. ${ }^{10}$ The authors set out to analyze the use of both fibula nails and talo-tibial-calcaneal (TTC) implants in the management of fragility ankle fractures. The review only included studies published until December 2015. Our systematic review included three further studies not previously reported by Jordan et al. ${ }^{10}$

\subsection{Selection criteria}

Studies published from the inception of data until September 2019 that assess the effectiveness of HFN in patients with osteoporotic ankle fractures were included. Inclusion and Exclusion criteria are outlined in Table 2. Articles meeting the inclusion criteria were read in full and assessed against the eligibility criteria.

\subsection{Source of material and search terms}

Search terms used with Boolean operators were applied in different online search engines to obtain studies that address the topic of this review (Table 3). The search began in December 2016 and was regularly updated up to September 2019. Manual review of the lists of references from retrieved publications was carried out to include studies potentially meeting the inclusion criteria that were not accessed by our online search. The full paper was retrieved when the title or abstract revealed insufficient information to determine suitability for inclusion. Replicas of the obtained studies from our search strategy were eliminated. All studies were assessed by two independent reviewers against the inclusion criteria for inclusion in our systematic review. Disagreements between the researchers were resolved by a consensus meeting.

Our primary search revealed 48 studies. After carefully evaluating their titles, 9 studies were selected for abstract review. Of these nine abstracts, two further papers were excluded as they did not meet our inclusion criteria (Fig. 1 Summarise search process). Seven articles met our criteria and used in the review (Table 4). The reviewers then agreed on the nature of data to be collected from the included studies on spreadsheets to determine the answers for the primary questions. Collected data included participants' demographics, details of intervention, outcomes, union rates, follow-up, and complications.

The pooling of the overall outcome could not be achieved because of the heterogeneity in findings. This heterogeneity originated from the fact that not all papers commented on the same clinical or functional outcomes. For instance, union rate, pain level, functional scores or weight-bearing status were mentioned in most but not all the included

Table 1

Summary of research terms.

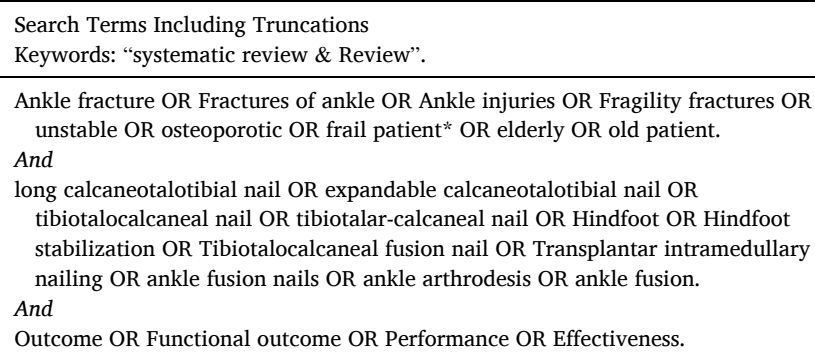

Outcome OR Functional outcome OR Performance OR Effectiveness.

Table 2

Eligibility criteria list.

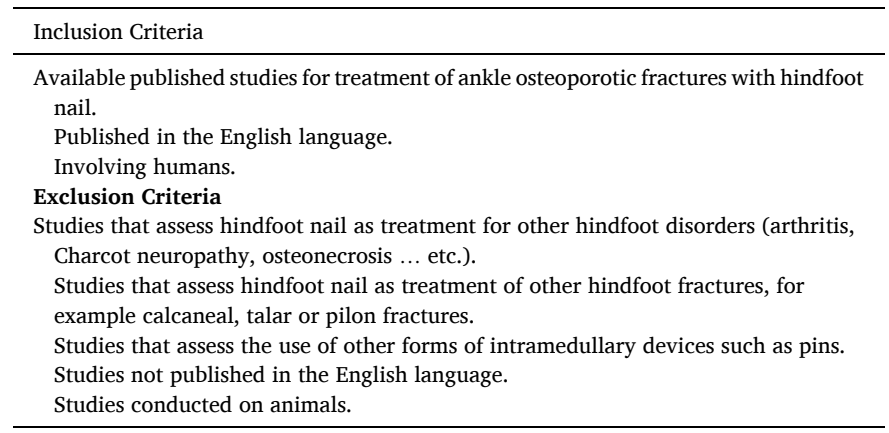

Table 3

Mesh terms applied according to PICO criteria.

\begin{tabular}{lll}
\hline Population & Intervention & Outcome \\
\hline Ankle fracture & long calcaneotalotibial nail & Outcome \\
Fracture of ankle & expandable calcaneotalotibial nail & Functional outcome \\
Ankle injuries & tibiotalocalcaneal nail & Performance \\
Fragility fractures & tibiotalar-calcaneal nail & Effectiveness \\
unstable & Hindfoot & \\
osteoporotic & Hindfoot stabilization & \\
frail patient & Tibiotalocalcaneal fusion nail & \\
elderly & Transplantar intramedullary nailing & \\
Old patient & ankle fusion nails & \\
& ankle arthrodesis & \\
& ankle fusion & \\
\hline
\end{tabular}

papers. Furthermore, between the selected studies there were differences in the nail type utilized (short versus long; locked versus expandable) and different structure of studies (6 prospective or retrospective case series, and one randomized controlled trial).

\subsection{Ethical issues}

The authors of this review have no conflict of interests to declare.

\section{Results}

Six case series and one randomized controlled trial included in our review. The total number of patients recruited was 194, of them, 145 were females and 49 males. The age range of all cases was 37-98 years (mean 76.39 years). Patients' demographic data, follow-up duration, Postoperative weight-bearing status, postoperative complications, mortality and Olerud and Molander score (OMAS) scores are summarized in Table 4.

Lemon et al. published a case series assessing the outcomes of retrograde calcaneotalotibial expandable nail for fragility ankle fractures. ${ }^{5}$ It reported 12 cases of fragility ankle fracture treated with an expandable intramedullary humeral nail between 2002 and 2003. All fractures reported to be fully healed. $71 \%$ of patients returned to preinjury mobility status and achieved an average postoperative OMAS of 61.4 compared to pre-operative average score of 69 . Half the patients opted to not have their nail removed as they reported better ankle stability postoperatively. There was no evidence of degenerative changes related to the nail.

Amirfeyz et al. conducted a case series of 13 patients between January 1999 to June 2, 005. ${ }^{8}$ The ACE retrograde locked intramedullary Calcaneo-tibial nail was used between 1999 and 2004 before a change to the retrograde locked ACE TTC (Trans Talo-Calcaneal) fusion nail from 2004 onwards. The nail used as a primary fixation in nine patients and as a secondary fixation after failed initial management in the remaining 4 cases. The patients allowed to mobilize partially weight-bearing postoperatively for 6 weeks. The mean postoperative 


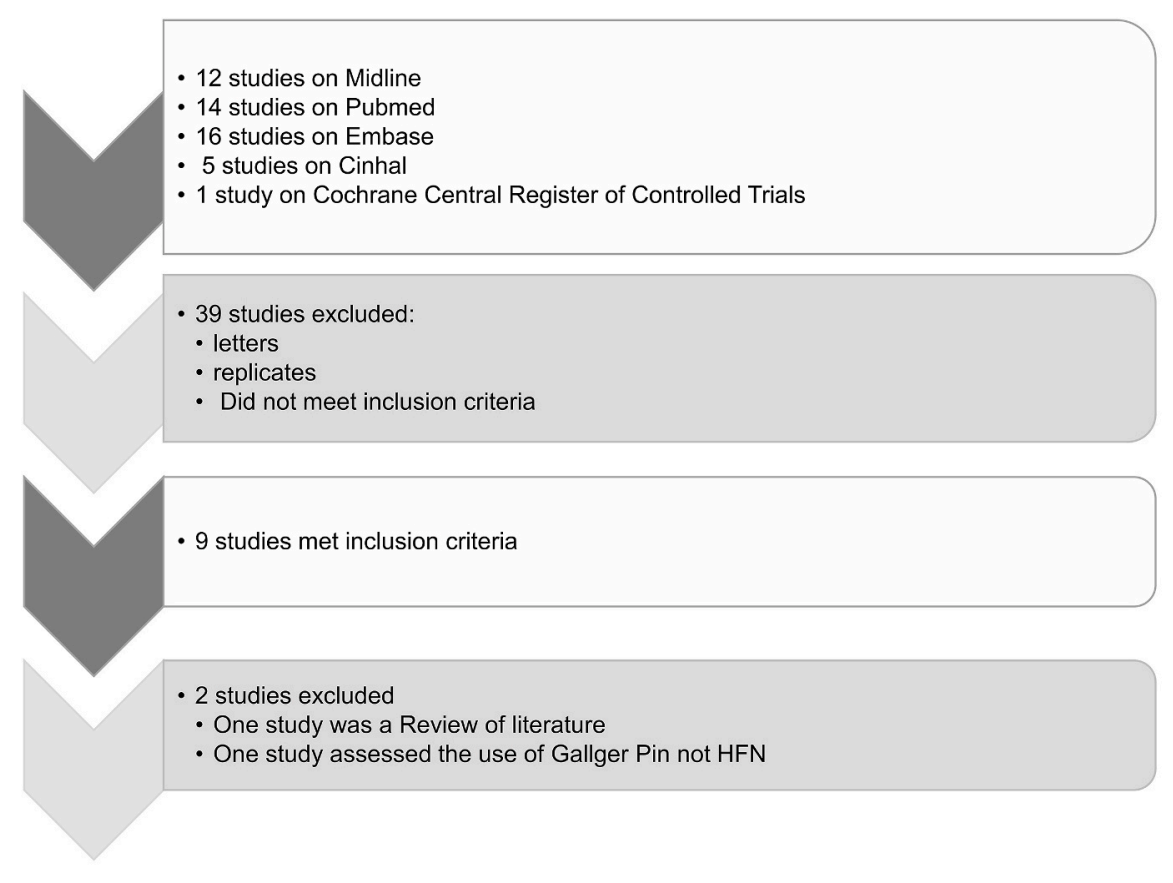

- Seven studies were included

Fig. 1. Flow chart of the search process.

HFN: Hindfoot Nail.

OMAS score was 50.

Another case series by Jonas et al. assessed the outcome of 31 consecutive patients between September 2008 and November 2011 following treatment of ankle fracture with a Trigen IM nail. ${ }^{2}$ Patients allowed to fully weight bear immediately post-surgery.

Al-Nammari et al. and Baker, Mayne, \& Andrews assessed the use of a T2 retrograde long femoral nailing system in the management of fragility ankle fractures. ${ }^{11,12}$ Al-nammari et al. reported that Postoperatively, all cases achieved union in a mean time of nine weeks. The mortality rate at six months was reported at $35.6 \%$. No periprosthetic fracture was reported. ${ }^{11}$ Baker, Mayne, \& Andrews reported a routine follow-up up to 6 weeks post-surgery, afterward, only 8 patients were available for telephone review (mean 21 months postoperatively), all of 8 patients who had a telephone review reported they returned to their pre-injury mobility level. No patient had a radiograph available at the final follow-up to assess bony union. ${ }^{12}$

Taylor et al. reviewed a case series of 31 patients from January 2006 to December 2012 with a mean follow-up of 13.6 months. ${ }^{13}$ There were $25.8 \%$ open Injury and $54.8 \%$ were diabetic. The phoenix ankle arthrodesis nail was used in 29 cases while a short Synthes retrograde supracondylar femoral nail was used in the remaining two cases. The primary outcome was to assess union rate, infection and implant-related complications.

Georgiannos, Lampridis, \& Bisbinas conducted a randomized controlled trial comparing HFN (group 1) to ORIF (group 2) for the treatment of unstable ankle fractures in elderly. ${ }^{14}$ The trial excluded open fractures, high-energy mechanism of injury, pathological fractures and patients with serving peripheral vascular disease. There were 43 and 44 patients recruited to group one and group two, respectively. A Trigen hindfoot fusion nail was the implant used for IM fixation in group one patients and weight-bearing was permitted from day one postoperatively. Group 2 patients were required to remain non-weight-bearing for 6 weeks postoperatively. There was only mild difference between the postoperative OMAS scores in each of the two groups. Patients in group one treated with HFN were reported to have a significantly reduced inpatient admission. Group 1 patient length of stay was 5.2 days (sd:3.1) compared to 8.4 days (sd: 5.2 ) in group 2 .

\section{Discussion}

There is no current consensus regarding the optimal treatment of fragility ankle fractures. ${ }^{15}$ The conventional treatment methods routinely used (including conservative management, or internal fixation), often provide poor outcomes and risk significant complications (such as non-union/malunion, fixation failure, and DVT) when applied within the geriatric population. ${ }^{3}$ This is often multifactorial and can be a result of poor quality skin and soft tissues, osteoporosis and decreased holding strength, and poor mobility. ${ }^{3,4,16}$ Recently, HFN has been utilized for the treatment of these osteoporotic ankle fractures. ${ }^{3}$ The aim is to achieve fracture stability and to allow early rehabilitation to avoid worsening of pre-existent medical illness and associated independent living or nursing care. ${ }^{2}$

\subsection{Surgical indications}

Most of the studies in this systematic review investigating HFN have outlined their indications to insert TTC nail for ankle fragility fractures. The indications included: Frail elderly patients (more than 60 years), poor soft tissue or bone quality (osteopenia and/or history of fragility fractures), and salvage procedure for failed previous operative fixation.

Given that six papers out of seven assessed in the current review are case series, the patient cohort will be prone to selection bias, which is the surgeon's choice directed the nature of treatment in these cases. With the absence of a randomized treatment allocation and defined selection 
Table 4

Summary of findings of the seven papers included in this systemic review.

\begin{tabular}{|c|c|c|c|c|c|c|c|c|c|c|}
\hline & \multirow{2}{*}{$\begin{array}{l}\text { Type } \\
\text { of } \\
\text { study }\end{array}$} & \multirow{2}{*}{$\begin{array}{l}\text { Sample } \\
\text { size }\end{array}$} & \multirow[t]{2}{*}{ Duration } & \multirow{2}{*}{$\begin{array}{l}\text { Mean } \\
\text { age \& } \\
\text { gender }\end{array}$} & \multirow{2}{*}{$\begin{array}{l}\text { Follow-up } \\
\text { (months) }\end{array}$} & \multirow{2}{*}{$\begin{array}{l}\text { Postoperative } \\
\text { mobilization }\end{array}$} & \multirow{2}{*}{$\begin{array}{l}\text { Complication } \\
\% \text { (number of } \\
\text { cases with details) }\end{array}$} & \multirow{2}{*}{$\begin{array}{l}\text { Mortality } \\
\% \text { (number of } \\
\text { mortalities } \\
\text { with details) }\end{array}$} & \multicolumn{2}{|l|}{ OMAS score } \\
\hline & & & & & & & & & Preoperatively & Postoperatively \\
\hline Lemon et al. ${ }^{5}$ & $\begin{array}{l}\text { Case } \\
\text { series }\end{array}$ & 12 & $2002-2003$ & $\begin{array}{l}84 \text { Years } \\
100 \% \\
\text { females }\end{array}$ & 16 & $\begin{array}{l}\text { Full Weight } \\
\text { Bearing }\end{array}$ & $8.3 \%$ (1 DVT) & $\begin{array}{l}25 \% \text { ( } 4 \text { cases. } \\
\text { Three not } \\
\text { related to } \\
\text { surgery) }\end{array}$ & 61.4 & 69.6 \\
\hline $\begin{array}{c}\text { Amirfeyz } \\
\text { et al. }\end{array}$ & $\begin{array}{l}\text { Case } \\
\text { series }\end{array}$ & 13 & 1999-2005 & $\begin{array}{l}78.9 \\
\text { years } \\
12 \\
\text { females, } \\
1 \text { male }\end{array}$ & 11 & $\begin{array}{l}\text { Partial Weight } \\
\text { Bearing }\end{array}$ & $\begin{array}{l}23 \% \text { ( } 1 \text { delayed } \\
\text { union, } 1 \\
\text { superficial } \\
\text { infection, } 1 \\
\text { needed nail } \\
\text { removal) }\end{array}$ & $\begin{array}{l}46 \% \text { ( } 6 \text { cases. } \\
\text { Five not } \\
\text { related to } \\
\text { surgery) }\end{array}$ & & 50 \\
\hline Jonas et al. ${ }^{2}$ & $\begin{array}{l}\text { Case } \\
\text { series }\end{array}$ & 31 & $2008--2011$ & $\begin{array}{l}77 \text { years } \\
21 \\
\text { females, } \\
10 \text { males }\end{array}$ & 8 & $\begin{array}{l}\text { Full Weight } \\
\text { Bearing }\end{array}$ & $\begin{array}{l}22.58 \% \text { ( } 3 \\
\text { periprosthetic } \\
\text { fracture, } 2 \text { broken } \\
\text { nails, } 2 \text { required } \\
\text { removal of distal } \\
\text { screws) }\end{array}$ & $\begin{array}{l}29 \% \text { ( } 9 \text { cases, } \\
\text { all not related } \\
\text { to surgery) }\end{array}$ & 56 & 45 \\
\hline $\begin{array}{l}\text { Al-Nammari } \\
\quad \text { et al. }{ }^{11}\end{array}$ & $\begin{array}{l}\text { Case } \\
\text { series }\end{array}$ & 48 & & $\begin{array}{l}82 \text { years } \\
41 \\
\text { females, } \\
7 \text { males }\end{array}$ & 6 & $\begin{array}{l}\text { Full Weight } \\
\text { Bearing }\end{array}$ & $\begin{array}{l}18.75 \% \text { (2 } \\
\text { Superficial } \\
\text { infection; } 1 \text { deep } \\
\text { infection; } 3 \text { a } \\
\text { broken or loose } \\
\text { distal locking } \\
\text { screw; } 2 \text { valgus } \\
\text { malunion; } 1 \\
\text { below-knee } \\
\text { amputation) }\end{array}$ & $\begin{array}{l}35 \%(17 \\
\text { cases. } 9 \text { not } \\
\text { related to } \\
\text { surgery) }\end{array}$ & 62 & 57 \\
\hline $\begin{array}{l}\text { Taylor } \\
\quad \text { et al. }\end{array}$ & $\begin{array}{l}\text { Case } \\
\text { series }\end{array}$ & 31 & 2006-2012 & $\begin{array}{l}63 \text { years } \\
17 \\
\text { females, } \\
14 \text { males }\end{array}$ & 13.6 & $\begin{array}{l}\text { Partial/full } \\
\text { Weight Bearing }\end{array}$ & $\begin{array}{l}29 \% \text { ( } 2 \text { superficial } \\
\text { and } 3 \text { deep } \\
\text { infections, } 3 \\
\text { asymptomatic } \\
\text { screw breaks, and } \\
1 \text { amputation) }\end{array}$ & $\begin{array}{l}\text { Not } \\
\text { mentioned }\end{array}$ & Not mentioned & \\
\hline Baker et al. ${ }^{12}$ & $\begin{array}{l}\text { Case } \\
\text { Series }\end{array}$ & 16 & 2014-2017 & $\begin{array}{l}73 \text { years } \\
12 \\
\text { females, } \\
4 \text { males }\end{array}$ & $\begin{array}{l}21 \\
\text { (telephone } \\
\text { review) }\end{array}$ & $\begin{array}{l}\text { Non-weight } \\
\text { bearing } 7-10 \\
\text { days, followed } \\
\text { by weight- } \\
\text { bearing as } \\
\text { tolerated }\end{array}$ & $\begin{array}{l}0 \% \text { (No reported } \\
\text { complications) }\end{array}$ & $\begin{array}{l}25 \% \text { ( } 4 \text { cases, } \\
\text { one from } \\
\text { hospital- } \\
\text { acquired } \\
\text { pneumonia } \\
\text { prior to } \\
\text { discharge, } \\
\text { and } 3 \\
\text { unrelated to } \\
\text { surgery) }\end{array}$ & Not mentioned & \\
\hline \multirow[t]{4}{*}{$\begin{array}{l}\text { Georgiannos } \\
\text { et al. } .^{14}\end{array}$} & $\begin{array}{l}\text { Nail } \\
\text { group }\end{array}$ & 43 & $\begin{array}{l}2009 \text { and } \\
2015\end{array}$ & $\begin{array}{l}78 \text { years } \\
30 \\
\text { females, } \\
13 \text { males }\end{array}$ & 12 & $\begin{array}{l}\text { Full Weight } \\
\text { Bearing }\end{array}$ & $\begin{array}{l}7 \% \text { ( } 3 \text { cases: DVT, } \\
\text { non-union, } \\
\text { metalwork } \\
\text { prominence) } \\
\text { required } \\
\text { reoperation }\end{array}$ & $\begin{array}{l}\text { Not } \\
\text { mentioned }\end{array}$ & $\begin{array}{l}\text { Not } \\
\text { mentioned }\end{array}$ & 61 \\
\hline & $\begin{array}{l}\text { ORIF } \\
\text { group }\end{array}$ & 44 & & $\begin{array}{l}77 \text { years, } \\
33 \\
\text { females }\end{array}$ & 12 & $\begin{array}{l}\text { None-Weight } \\
\text { Bearing }\end{array}$ & $\begin{array}{l}27.3 \% \text { ( } 12 \text { cases } \\
5 \text { reoperations) }\end{array}$ & $\begin{array}{l}\text { Not } \\
\text { mentioned }\end{array}$ & 56.9 & 56.6 \\
\hline & & Total & & & & & Overall & & & \\
\hline & & $\begin{array}{l}H F N= \\
194\end{array}$ & & & & & $\begin{array}{l}\text { Complications } \\
\text { rate }=16.49 \%\end{array}$ & & & \\
\hline
\end{tabular}

criteria, the case-control studies would prove difficult to reproduce. The authors were aware of the limitations of the study design and have recommended that further idealized studies should be undertaken in the shape of a prospective randomized controlled trial with long term follow-up.

Lemon et al. \& Jonas et al. found a correlation between the level of mobility before the injury and the application of HFN as an implant for treatment of fragility ankle fractures in their cohort of patients. ${ }^{2,5}$ In addition, the authors recommended the use of HFN nail for less active patients with limited weight-bearing potential. Surgeons who treat fragility ankle fractures often use HFN/IM nail devices for elderly less active patients and use internal fixation implants for younger active patients. ${ }^{17}$

\subsection{Type of nail}

All seven studies used different types of intramedullary nails for surgical fixation of ankle fractures. Each possessing slightly different physical properties and mechanical principles. Each different nail may have its own advantages and disadvantages, and often surgeon preference and equipment availability play a role. One of the more contentious issues associated with the use of short locking nails is the diaphyseal stress riser effect and associated risk of periprosthetic fracture. ${ }^{2}$ Jonas et al. reported three cases in their cohort suffered periprosthetic fractures, yet, no periprosthetic fractures have been reported in any of the earlier two studies which applied short locking nails (Lemon et al., 2003; Amirfyz et al., 2008). ${ }^{2,5,8}$ However, small sample sizes and short follow-up periods could attribute to the low reported rates of 
periprosthetic fracture in both studies.

Al-Nammari et al. and Baker, Mayne, \& Andrews in their retrospective study utilized long-locked nails to avoid stress riser effects and periprosthetic fractures. No periprosthetic fracture reported during the follow-up period. ${ }^{11,12}$

\subsection{Surgical approaches and intra-operative issues}

The percutaneous minimally invasive technique used with HFN has several intraoperative benefits in comparison to open reduction techniques. The HFN technique allows a shorter operative time, reduced intraoperative blood loss and reduced soft tissue dissection when compared to open reduction. ${ }^{13}$

\subsection{Union}

Al-Nammari et al.; Amirfyz et al.; Lemon et al.; and Jonas et al. reported a $100 \%$ union rate among all patients in their groups treated with HFN technique based on clinical examination and X-ray evidence. ${ }^{2,5,8,11}$ Taylor et al. reported the incidence of non-union to be at $10 \%$ in their case series of patients treat with HFN. ${ }^{13}$ The authors failed to report on any potential causes of non-union or further ongoing management. Nevertheless, in cases of asymptomatic non-union, revision is rarely indicated as it is believed that the nail will continue to splint the fracture. ${ }^{18}$

The rate of union reported to be $86.7 \%$ in a systematic review included 651 cases treated with HFN by Jehan et al., in $2011,{ }^{19}$ with an average time to union of 4.5 months. However, the remaining patients who had non-union, only $26 \%$ required a revision, as the majority of patients with non-union either remained asymptomatic or were able to coup with their symptoms. ${ }^{19}$ This suggests that, in the event of non-union, HFN can continue to maintain stability across the fracture.

\subsection{Olerud and Molander scoring system (OMAS) and postoperative functional status}

Al-Nammari et al. and Amirfeyz et al. reported that most patients treated with HFN returned to their pre-operative functional level with a slight, but insignificant, decrease in the postoperative OMAS score. ${ }^{8,11}$ The authors accounted for this to the obliteration of the tibiotalar and subtalar joint movement. Despite, they reported that $75.6 \%$ of patient with HFN returned to their preoperative mobility level, compared to $72.2 \%$ in the ORIF group.

\subsection{Weight-bearing and hospital stay}

HFN is an intramedullary load sharing device. It is recommended that the patient treated with HFN should be allowed to fully weight-bear immediately after surgery. In contrast to the traditional ORIF technique, which usually requires up to 6 weeks of non-weight bearing postoperatively. Georgiannos, Lampridis, \& Bisbinas reported that HFN resulted in a shorter duration of hospital stay, earlier rehabilitation, and reduced risk of complications. ${ }^{14}$

The aims of treating fragility ankle fractures could be considered similar to managing the elderly neck of femur/hip fractures. Where the key goal is to facilitate early postoperative mobilization, avoid complications, and to restore early postoperative function and daily activities. In contrast to younger patients were restoring the anatomy of the joint is the main goal. . $20,21^{2}$

\subsection{Complications}

The overall complication rate was $16.49 \%$ (32 cases) in this systematic review. Table 5 summarises the different complications reported from the 7 papers included in this review. The complication rates are comparable to a systematic literature review conducted by Jehan et al.
Table 5

Postoperative complications.

\begin{tabular}{lc}
\hline Complications & Percent \\
\hline DVT & $1.03 \%$ \\
delayed union, non-union, and malunion & $2.06 \%$ \\
superficial and deep infection & $4.63 \%$ \\
need for nail removal & $1.03 \%$ \\
periprosthetic fracture & $1.54 \%$ \\
Metalwork complication broken nails or screw & $5.67 \%$ \\
Below knee amputation & $1.03 \%$ \\
Need for another surgery & $5.15 \%$ \\
\hline
\end{tabular}

where complications of HFN ranged from $15 \%$ to $50 \%$ in the included studies. ${ }^{19}$ By adhering to proper soft-tissue handling, using sound surgical technique, ensuring adequate fixation and managing the patients' medical comorbidities, the complication rates associated with HFN can be drastically reduced. ${ }^{22}$ It is recommended that patients should be fully counseled about the risks associated with HFN fixation, highlighting the considerable risk of significant complications including amputation and reoperation.

\subsection{Mortality rate}

The mortality rate reported in the studies included in this review ranged from $25 \%$ to $46 \%$ at the final follow-up (Table 4 ). These figures are close to the reported one-year mortality rate following fragility hip fracture $(33 \%))^{23}$

This is believed to be multifactorial: the high rate of medical comorbidities and frailty seen within-population suffering such injuries is believed to be the main cause. Switzer, \& Gammon had demonstrated the potential benefit of involving a geriatrician in the in-hospital care of patients suffering from fragility ankle fractures, as this can reduce the length of stay, readmission rates, complication rates, and overall patient mortality. ${ }^{24}$

\subsection{Risk of arthritis}

The HFN technique often creates damage to the articular surfaces of the ankle and subtalar joints during insertion. This recognized articular joint damage can theoretically lead to accelerated arthritic changes. Hence, Lemon et al. have suggested that the removal of the nail after achieving bony union may reduce the potential risk of arthritis. ${ }^{5}$ However, Childress in his study after following up 92 patients for around 16 years, have not noticed any radiological evidence of degenerative changes in ankle and subtalar joints. ${ }^{25}$ However, in his cohort, Childress only utilizes Steinmann pins rather than the wider HFN nails.

There are other factors that can influence the development of posttraumatic osteoarthritis after ankle fractures, including the reduction and alignment of the fracture, stability at the fracture site, fracture mechanism and cartilage damage caused by the initial injury. ${ }^{26} \mathrm{~A}$ systematic review by Stufkens et al. reviewed 1822 surgically treated ankle fractures, reporting that $79.3 \%$ of optimally reduced fractures have good - excellent long-term results. ${ }^{26}$ They concluded that malunion is the most important factor determining the long-term outcome after ankle fracture and attributed the development of arthritis in the remaining $20.7 \%$ to other factors such as mechanism of injury and initial cartilage lesions. ${ }^{26}$ In our systematic review, there were only two reported cases who had valgus malunion following fixation with HFN. Based on this, the author would not recommend removing the implant after achieving a union to avoid osteoarthritis as suggest by Lemon et al. ${ }^{5}$

\subsection{Nail removal}

There were conflicting views among authors included in this review regarding the removal of HFN following bony union. Lemon et al. recommended removal of the nail after establishment of union at the 
fracture site, while others did not. ${ }^{2,5,11}$ The indications for the removal of the nail included avoiding potentially periprosthetic fractures and the potential for accelerated degenerative process. ${ }^{5}$ Despite Lemon et al. recommending the removal of the nail to patients, only $50 \%$ agreed to it, and there was on differences in arthritic changes at the final follow-up. ${ }^{5}$

Al-Nammari et al. found that eliminating hindfoot joint movement at the tibiotalar and subtalar joints does not impair the overall foot function. ${ }^{11}$ Jonas et al. advised against the routine removal of the nails to avoid subjecting these elderly patients to unnecessary surgical risks. ${ }^{2}$

\subsection{Limitations and implications for future researches}

One of the limitations of this review is that the studies included have small sample sizes and short periods of follow-up. Although this study does completely eliminate the current controversy and does not establish with confidence the optimal management strategy of fragility ankle fractures, It will form the basis for future prospective randomized controlled trial comparing the outcome of HFN and conventional methods in treating fragility ankle fractures with long term follow-up.

\section{Conclusion and summary}

Fragility ankle fractures are an increasingly prevalent clinical condition. These injuries are challenging to treat and pose significant risks and morbidity to patients. Treatment goals for the elderly low demand population who suffer from these injuries should be focused on facilitating early full weight-bearing and prompt restoration of functional autonomy. Conventional methods of treatment, conservative or operative, often fail to achieve these goals and have high complication rates. The use of HFN to treat fragility ankle fractures should be considered in these patients as we have found that it has favorable outcomes regarding early rehabilitation, restoration of function and length of hospital stay. There was evidence to support that short HFN could be associated with a higher risk of periprosthetic fracture compared to long HFN. The union rate was high after using HFN and few patients had non-union. In case of non-union, there was an evidence to suggest that the nail can be left as it will continue to splint the ankle, unless if it is symptomatic. The use of HFN does not appear to accelerate the degenerative changes in the ankle joints and we would recommend that routine removal of the implant should be limited only for symptomatic patients. Further prospective randomized controlled trials comparing the outcome of patients with fragility ankle fractures treated with HFN vs conventional treatments should be conducted, preferably with longer periods of follow-up.

\section{Declaration of competing interest}

No conflict of Interest to declare.

\section{Acknowledgment}

The authors declare that no part of this study has been taken from existing published or unpublished materials without due acknowledgment and that all secondary materials used herein has been fully referenced.

This research did not receive any specific grant from funding agencies in the public, commercial, or not-for-profit sectors.

\section{References}

1 Kannus P, Palvanen M, Niemi S, Parkkari J, Jrvinen M. Increasing number and incidence of low-trauma ankle fractures in elderly people: Finnish statistics during 1970-2000 and projections for the future. Bone. 2002;31(3):430-433.

2 Jonas S, Young A, Curwen C, McCann P. Functional outcome following tibio-talarcalcaneal nailing for unstable osteoporotic ankle fractures. Injury. 2013;44(7): 994-997.

3 Hoogervorst P, Van Bergen C, Van den Bekerom M. Management of osteoporotic and neuropathic ankle fractures in the elderly. Current geriatrics reports. 2017;6(1):9-14.

4 Mears SC, Kates SL. A guide to improving the care of patients with fragility fractures, edition 2. Geriatr Orthop Surg Rehabil. 2015;6(2):58-120.

5 Lemon M, Somayaji H, Khaleel A, Elliott D. Fragility fractures of the ankle: stabilisation with an expandable calcaneotalotibial nail. J Bone Jt Surg Br Vol. 2005; 87(6):809-813.

6 Buckingham R, Hepple S, Winson I. Outcome of ankle fractures in the elderly. Foot Ankle Surg. 2000;6(3):175-178.

7 Willett K, Keene DJ, Morgan L, et al. Ankle Injury Management (AIM): design of a pragmatic multi-centre equivalence randomised controlled trial comparing Close Contact Casting (CCC) to Open surgical Reduction and Internal Fixation (ORIF) in the treatment of unstable ankle fractures in patients over 60 years. BMC Muscoskel Disord. 2014;15(1):79.

8 Amirfeyz R, Bacon A, Ling J, et al. Fixation of ankle fragility fractures by tibiotalocalcaneal nail. Arch Orthop Trauma Surg. 2008;128(4):423-428.

9 Jordan RK, Bafna KR, Liu J, Ebraheim NA. Complications of talar neck fractures by Hawkins classification: a systematic review. J Foot Ankle Surg. 2017;56(4):817-821.

10 Jordan R, Chapman A, Buchanan D, Makrides P. The role of intramedullary fixation in ankle fractures-a systematic review. Foot Ankle Surg. 2018;24(1):1-10.

11 Al-Nammari S, Dawson-Bowling S, Amin A, Nielsen D. Fragility fractures of the ankle in the frail elderly patient: treatment with a long calcaneotalotibial nail. $J$ Bone Joint. 2014;96(6):817-822.

12 Baker G, Mayne A, Andrews C. Fixation of unstable ankle fractures using a long hindfoot nail. Injury. 2018;49(11):2083-2086.

13 Taylor BC, Hansen DC, Harrison R, Lucas DE, Degenova D. Primary retrograde tibiotalocalcaneal nailing for fragility ankle fractures. Iowa Orthop J. 2016;36:75.

14 Georgiannos D, Lampridis V, Bisbinas I. Fragility fractures of the ankle in the elderly: open reduction and internal fixation versus tibio-talo-calcaneal nailing: short-term results of a prospective randomized-controlled study. Injury. 2017;48(2):519-524.

15 Donken CC, Al-Khateeb H, Verhofstad MH, van Laarhoven CJ. Surgical versus conservative interventions for treating ankle fractures in adults. Cochrane Database Syst Rev. 2012;8.

16 Willett K, Hearn T, Cuncins A. Biomechanical testing of a new design for Schanz pedicle screws. J Orthop Trauma. 1993;7(4):375-380.

17 Woods JB, Burns PR. Advances in intramedullary nail fixation in foot and ankle surgery. Clin Podiatr Med Surg. 2011;28(4):633-648.

18 Papa JA, Myerson M. Pantalar and tibiotalocalcaneal arthrodesis for post-traumatic osteoarthrosis of the ankle and hindfoot. JBJS. 1992;74(7):1042-1049.

19 Jehan S, Shakeel M, Bing A, Hill SO. The success of tibiotalocalcaneal arthrodesis with intramedullary nailing: a systematic review of the literature. Acta Orthop Belg. 2011;77(5):644.

20 McFadyen I, Aqil (iii) A. The osteoporotic ankle fracture. J Orthop Traumatol. 2011; 25(4):253-257.

21 Müller ME, Allgöwer M, Allgower M, Schneider R, Willenegger H. Manual of Internal Fixation: Techniques Recommended by the AO-ASIF Group. Springer Science \& Business Media; 1991.

22 Zaghloul A, Haddad B, Barksfield R, Davis B. Early complications of surgery in operative treatment of ankle fractures in those over 60: a review of 186 cases. Injury. 2014:45(4):780-783.

23 Keene GS, Parker MJ, Pryor GA. Mortality and morbidity after hip fractures. BMJ. 1993;307(6914):1248-1250.

24 Switzer JA, Gammon SR. High-energy skeletal trauma in the elderly. JBJS. 2012;94 (23):2195-2204.

25 Childress HM. Vertical transarticular pin fixation for unstable ankle fractures: impressions after 16 years of experience. Clin Orthop Relat Res. 1976;(120):164-171.

26 Stufkens SA, van den Bekerom MP, Kerkhoffs GM, Hintermann B, van Dijk CN. Longterm outcome after 1822 operatively treated ankle fractures: a systematic review of the literature. Injury. 2011;42(2):119-127. 